\title{
Effect of Food Intake on Growth and Survival of Salmonellas and Escherichia coli in the Bovine Rumen
}

\author{
By L. E. BROWNLIE AND F. H. GRAU \\ Meat Research Laboratory, Division of Food Preservation, \\ Commonwealth Scientific and Industrial Research Organization, \\ Cannon Hill, Brisbane, Queensland, Australia
}

(Accepted for publication 17 August 1966)

\begin{abstract}
SUMMARY
When salmonella organisms were put into the rumen of cattle their subsequent growth or elimination depended on the dietary intake before and after the organisms were ingested. When the animals were receiving a regular daily ration of $6.8 \mathrm{~kg}$. lucerne hay the organisms were rapidly eliminated from the rumen and viable organisms in the faeces were rarely detected. Decreasing the daily food intake to $2.3 \mathrm{~kg}$. or interruption of feeding for one or more days retarded the elimination of salmonellas and Escherichia coli or permitted their growth in the rumen. Growth of salmonellas and E. coli type I occurred during starvation, and resumption of feeding after starvation caused further multiplication. Starvation for 2 or 3 days was generally followed by infection of the intestine, with salmonellas persisting in the faeces for at least a week.
\end{abstract}

\section{INTRODUCTION}

In an earlier study Grau \& Brownlie (1965) showed that at five abattoirs in southeastern Queensland salmonella organisms occurred in the rumen contents of $45 \%$ of healthy cattle at slaughter. Escherichia coli type I at about $10^{5}$ organisms $/ \mathrm{ml}$. were also found in the rumen fluid, in agreement with other reports on the occurrence of E. coli (Mann, Masson \& Oxford, 1954).

The work described in the present paper was undertaken to ascertain the fate of known numbers of salmonella organisms put into the rumen, and to determine concomitant changes in the population of Escherichia coli. The effect of deprivation of foodstuff was also examined, as it is common for cattle to be given little or no food for several days while being moved long distances or held at abattoirs. Deprivation of food may be a predisposing condition for infection in ruminants (Salisbury, 1958; Seddon, 1953).

\section{METHODS}

The salmonella organisms used were Salmonella chester, S. typhimurium, $S$. oranienburg, S. muenchen, $S$. anatum and $S$. adelaide, these having been isolated from the rumens of cattle at slaughter and identified by Dr K. F. Anderson (Salmonella Reference Centre, Adelaide). Cultures were grown in $0.8 \%(\mathrm{w} / \mathrm{v})$ nutrient broth (Difco) for two $24 \mathrm{hr}$ subcultures at $37^{\circ}$, and after suitable dilution in $0.1 \%(\mathrm{w} / \mathrm{v})$ peptone (Oxoid) water the salmonellas were inoculated into the rumens of the animals. 
The salmonellas were introduced into the stomach tube used for sampling (Raun \& Burroughs, 1962) and flushed into the rumen with $50 \mathrm{ml}$. rumen liquor previously taken from the animal. The number of salmonellas given was estimated by serial dilution of the inoculum with peptone water and pour-plating with plate-count agar (Oxoid); colonies were counted after incubation at $37^{\circ}$ for $24 \mathrm{hr}$. In some experiments the organisms were introduced into the rumen as a peptone water suspension of airdried faeces contaminated with salmonellas, the numbers of which were estimated by the most-probable-number technique described below.

The experimental cattle were Polled Hereford females from 18 months to 3 years of age. In the experiments reported the animals were confined in a cattle crush, to prevent their ingesting faecal material. They were usually fed $6.8 \mathrm{~kg}$. of lucerne hay, presented at the same time daily. In some experiments the animals were deprived of food, but not water, for various periods; while in others food was supplied in a limited amount $(2.3 \mathrm{~kg}$.) at the normal times. On the completion of an experiment the animals were treated with sulphadimidine (Mezobols, Parnell Laboratories, Carlton, N.S.W.) daily until faecal samples were consecutively negative. An animal was fed lucerne hay for a minimum of 2 weeks before an experiment was begun, or was grazed for about 6 weeks.

Samples of rumen fluid were obtained by the stomach-tube method, and after their transfer to the laboratory suitable samples of fluid or of peptone water dilutions of it, were subjected to enrichment as described by Grau \& Brownlie (1965). Tetrathionate Tergitol brilliant green broth enrichments were incubated at $37^{\circ}$ for $24 \mathrm{hr}$ and streaked on the surface of brilliant green sulphadiazine agar and aged bismuth sulphite agar. The selective media were incubated overnight at $37^{\circ}$ and colonies suspected of being salmonellas were suspended in saline and tested by slide agglutination with somatic antigens. The enrichments proven to contain salmonellas were eliminated from further incubation, those negative at the $24 \mathrm{hr}$ streaking were retained in incubation for a total of $72 \mathrm{hr}$ before restreaking. The enrichments positive for salmonellas after $24 \mathrm{hr}$ incubation were counted cumulatively with those found positive at the $72 \mathrm{hr}$ streaking. The most-probable-number of salmonellas, after $72 \mathrm{hr}$ enrichment, was estimated from the number of positive enrichments in ten tubes at each dilution (McCoy, 1962). Escherichia coli type I was estimated by serial dilution in peptone water and pour-plating with eosin methylene blue agar (Oxoid), counting the lactosepositive colonies greater than $0.5 \mathrm{~mm}$. in diameter after incubation at $44.5^{\circ}$ for $48 \mathrm{hr}$. Only 2 of 200 such colonies tested did not give typical reactions of $E$. coli type I. Faecal samples were examined for salmonellas by enrichment of two $5 \mathrm{~g}$. samples, each in $100 \mathrm{ml}$. of tetrathionate Tergitol brilliant green broth, following the procedure used for rumen samples. Representative isolates from faeces and rumen were identified by the Salmonella Reference Centre, Adelaide, and proved to be of the serotype inoculated.

$\mathrm{pH}$ measurements of the $\mathrm{pH}$ values of rumen fluids were made with a Radiometer pH meter and glass electrode after the bacterial samples were taken. The measurements were made about $30 \mathrm{~min}$. after removal from the animal and no precautions. were taken to maintain carbon dioxide in solution. Volatile fatty acids were determined in a $20 \mathrm{ml}$. sample of clarified rumen liquor by the methods outlined by Neish (1952). for clarification and distillation. Ammonia was determined on suitable samples of clarified rumen liquor by vacuum distillation from borate buffer $\mathrm{pH} 10$ (Varner, 
Bulen, Vanecko \& Burrell, 1953) into a boric acid trap, titrated by the technique of McKenzie \& Wallace (1954). Paper chromatography and thin-layer chromatography of acidified ether extracts of clarified rumen fluid were done by the methods of Gordon, Thornburg \& Werum (1962) and Ting \& Dugger (1965).

\section{RESULTS}

The effects of regular daily feeding with $6.8 \mathrm{~kg}$. lucerne hay/day

Four experiments were made to test the effect of inoculation of salmonellas into the rumens of animals fed $6.8 \mathrm{~kg}$. lucerne hay daily. These experiments involved three cattle and three different salmonella serotypes. The results of a typical experiment are shown in Fig. 1. In this experiment, air-dried faeces obtained from an animal shedding Salmonella chester was inoculated as a peptone water suspension. The inoculum contained $2.8 \times 10^{5}$ salmonellas, estimated by the most-probable-number technique. Salmonellas in the rumen decreased rapidly from $300 / 100 \mathrm{ml}$., and were not detectable $48 \mathrm{hr}$ after inoculation. In this experiment salmonellas were present in the faeces $24 \mathrm{hr}$ after inoculation, but not at later samplings. In three other experiments in which a similar inoculum of salmonellas, grown in nutrient broth, was used, the organisms were not detected in the rumen at or after $24 \mathrm{hr}$ and were not detected at any sampling of the faeces.

\section{The effects of regular daily feeding with $2 \cdot 3 \mathrm{~kg}$. lucerne hay/day}

Three experiments with three animals and two salmonella serotypes were made to test the effect of feeding $2.3 \mathrm{~kg}$. lucerne hay every day on changes in the numbers of salmonella and Escherichia coli type I organisms.

In the first experiment the inoculation with $3 \cdot 5 \times 10^{5}$ salmonellas was on the first day of the smaller feed and the numbers decreased from 161/100 ml. rumen liquor until they were undetected at $48 \mathrm{hr}$ when the experiment was terminated. In the second experiment the animal was given $1.4 \times 10^{6}$ salmonellas on the third day of decreased feeding. The numbers decreased from $693 / 100 \mathrm{ml}$. to $1 / 100 \mathrm{ml} .72 \mathrm{hr}$ after inoculation, when the experiment was terminated. Salmonellas were not detected in the faeces in either experiment.

In the experiment illustrated in Fig. 2, a larger inoculum of Salmonella oranienburg $\left(9.8 \times 10^{7}\right)$ was used to follow changes in the salmonella numbers in the rumen over a longer period of time. Initially the salmonella numbers in the rumen decreased, but from about 35 to $40 \mathrm{hr}$ after inoculation (i.e. $110 \mathrm{hr}$ from last $6.8 \mathrm{~kg}$. ration) there was a gradual increase until the animal was returned to a feed of $6.8 \mathrm{~kg}$. lucerne hay/day; then the number decreased abruptly. The Escherichia coli type I numbers increased for about $70 \mathrm{hr}$ after inoculation, then stabilized, and decreased when the animal was returned to $6.8 \mathrm{~kg}$. lucerne hay/day. The period of salmonella growth during feeding with $2 \cdot 3 \mathrm{~kg}$. hay/day may be related to that period when the volatile fatty acids value was low and the $\mathrm{pH}$ value high. When the volatile fatty acids value increased and the $\mathrm{pH}$ value decreased on feeding $6.8 \mathrm{~kg}$. lucerne/day, the numbers of salmonellas and $E$. coli decreased. A plot of $\mathrm{pH}$ value against the concentration of volatile fatty acids showed no points deviating from the approximate linear relation (Briggs, Hogan \& Reid, 1957), in contrast to the later experiments which involved a starvation period 
(Fig. 3). The faeces contained salmonellas from $24 \mathrm{hr}$ after inoculation until after remedial treatment with Mezobols.

\section{The effect of regular feeding on alternate days with $6.8 \mathrm{~kg}$. lucerne hay}

Three experiments were made to test the effect of alternate-day feeding; three animals and two salmonella serotypes were used. The results of one experiment are shown in Fig. 4: the inoculum was $2.1 \times 10^{8}$ Salmonella muenchen and was introduced during the second starvation period. The numbers decreased from an initial value of $5 \cdot 1 \times 10^{5} / 100 \mathrm{ml}$. rumen liquor to $1 \cdot 2 \times 10^{4} / 100 \mathrm{ml}$. at $24 \mathrm{hr}$ after inoculation. The numbers then tended to be maintained, with some fluctuations. From $24 \mathrm{hr}$ after inoculation, salmonellas were detected in the faeces for the duration of the experiment.

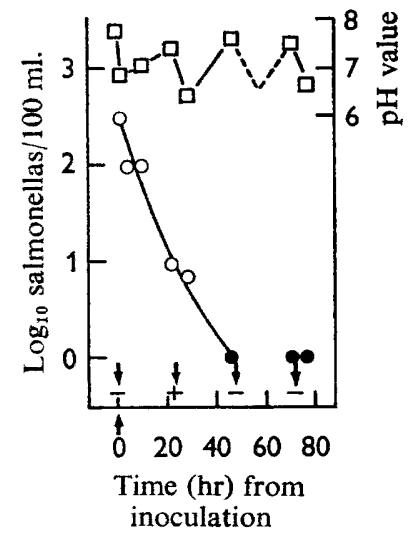

Fig. 1

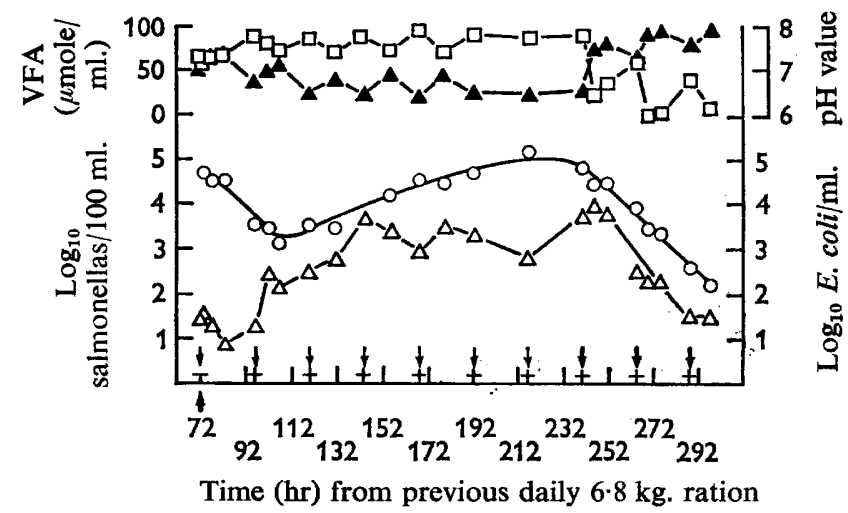

Fig. 2

Fig. 1. The effect on inoculated Salmonella chester (O) of regular daily feeding $6.8 \mathrm{~kg}$. lucerne hay $(\downarrow)$. , Salmonellas not detected in $10 \times 10 \mathrm{ml}$. rumen liquor samples; + , detected in faeces; - not detected in faeces. $\uparrow$, Time of inoculation with faeces suspension containing $2 \cdot 8 \times 10^{5}$ salmonellas. $\square, \mathrm{pH}$ value.

Fig. 2. The effect on Salmonella oranienburg $(O)$ and Escherichia coli type $I(\triangle)$ on inoculation $(\uparrow)$ of $9 \cdot 8 \times 10^{7}$ salmonellas into the rumen of an animal regularly fed $(\downarrow) 2 \cdot 3 \mathrm{~kg}$. lucerne hay/day. The animal was inoculated on the third day of diminished feeding. + , Salmonellas detected in the faeces; - not detected in faeces. $\square, \mathrm{pH}$ value; $\Delta, \mathrm{VFA}$, concentration of volatile fatty acids.

The Escherichia coli type I count increased during the second starvation period and also for 6-11 hr after each feed; in the period between feeds the numbers tended to decline. The $E$. coli numbers appeared to cycle roughly with the changes in volatile fatty acids. The plot of $\mathrm{pH}$ value against volatile fatty acids for this experiment (Fig. 3) shows two points off the approximate straight-line relation; these two points corresponded to the only two samples taken at $6 \mathrm{hr}$ after feeding. Most of the $E$. coli growth occurred within this $6 \mathrm{hr}$ period. The results of the other experiments were similar. In one experiment the salmonella fluctuations were greater and tended to parallel the $E$. coli fluctuations, except for a growth during the third starvation period.

\section{The effects of withholding food for 2 to 3 days}

Inoculation of salmonellas before feeding lucerne hay and before withholding food for 2 days. Salmonella chester $\left(2 \times 10^{8}\right)$ was inoculated into the rumen of one animal 
immediately before feeding (Fig. 5). Food was then withheld for 2 days before the animal was given a single feed of $6.8 \mathrm{~kg}$. lucerne hay. The number of salmonellas in the rumen was initially $3 \times 10^{5} / 100 \mathrm{ml}$. liquor, decreased to $916 / 100 \mathrm{ml}$. in $22 \mathrm{hr}$, remained constant for about $24 \mathrm{hr}$, and then increased a thousandfold at $48 \mathrm{hr}$ after the last feed. Only a slight increase occurred on feeding after this starvation. On withholding food for a further 3 days the numbers declined about one log unit per day. On a subsequent feed the number increased about 30 -fold.

The faeces contained salmonellas at $24 \mathrm{hr}$ after inoculation and then for the duration of the experiment.

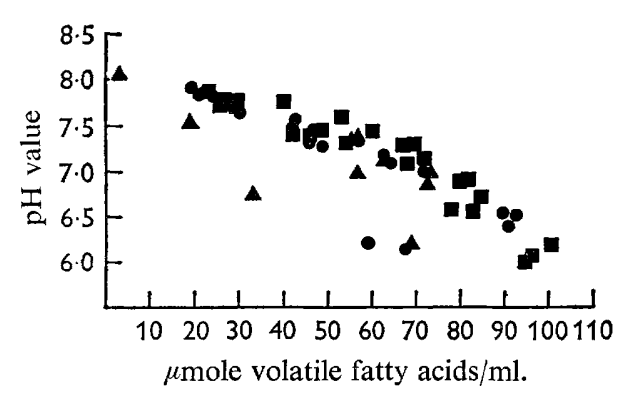

Fig. 3

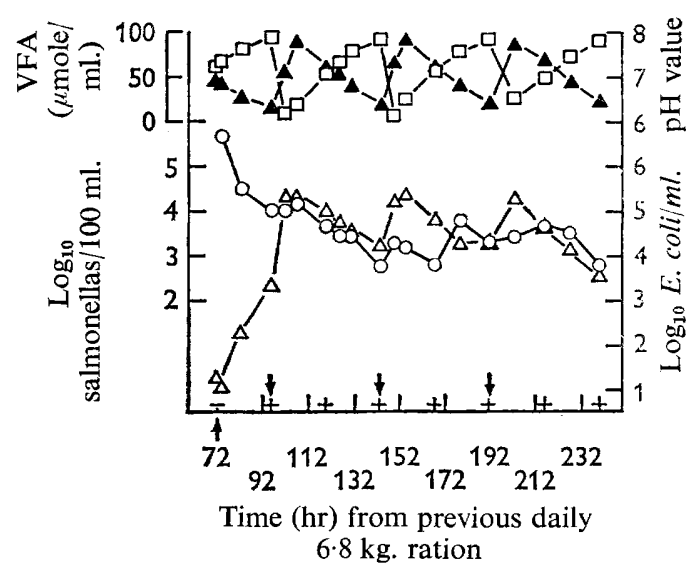

Fig. 4

Fig. 3. The relation between pH value and volatile fatty acids in rumen liquor. $\Delta$, Two days without food (see Fig. 7); $\bullet$, fed $6.8 \mathrm{~kg}$. lucerne hay every alternate day (see Fig. 4); $\mathbf{\square}$, fed $2 \cdot 3 \mathrm{~kg}$. lucerne hay daily (see Fig. 2).

Fig. 4. The effect on Salmonella muenchen $(O)$ and Escherichia coli type $\mathrm{I}(\triangle)$ on inoculation $(\uparrow)$ of $2 \cdot 1 \times 10^{8}$ salmonellas into the rumen of an animal fed $(\downarrow) 6.8 \mathrm{~kg}$. lucerne hay every alternate day. The animal was inoculated during the second starvation period. + , Salmonellas detected in faeces; - , not detected in faeces. $\square, \mathrm{pH}$ value; $\boldsymbol{\Lambda}$, VFA, concentration of volatile fatty acids.

From low numbers Escherichia coli type I increased during starvation by over $10^{5}$ times. A further increase of 30 -fold occurred on feeding, but the numbers decreased during the second starvation. A further increase was obtained on giving the final feed.

Inoculation of salmonellas $24 \mathrm{hr}$ after feeding lucerne hay and before withholding food for 2 days. In two experiments the animals were inoculated $24 \mathrm{hr}$ after feeding and then deprived of food for 2 days; the results of one experiment are shown in Fig. 6. The inoculum contained $3.8 \times 10^{5}$ Salmonella oranienburg and the initial concentration of salmonellas in the rumen liquor was $300 / 100 \mathrm{ml}$. The salmonella count initially decreased, but at about $54 \mathrm{hr}$ from the regular $6.8 \mathrm{~kg}$. feed the salmonellas began to grow and continued to increase for $24 \mathrm{hr}$ after the next feed, the total increase being about $3.5 \mathrm{log}$ units; on continued feeding the salmonella concentration fell daily about one log unit.

The Escherichia coli type I numbers in the rumen increased at about $35 \mathrm{hr}$ from the regular $6.8 \mathrm{~kg}$. feed and showed a further sharp increase on feeding after the 2-day starvation. Salmonellas were detectable in the faeces $24 \mathrm{hr}$ after inoculation and then 
for the duration of the experiments. The results of the second experiment were similar except that $E$. coli began to increase in numbers at about $50 \mathrm{hr}$ from the last feed and the count paralleled the changes in the numbers of salmonellas.

Inoculation of salmonellas before feeding and after food was withheld for 2 days. Two experiments using 2 animals and 2 salmonella serotypes were done to test the effect on inoculated salmonellas of feeding $6.8 \mathrm{~kg}$. lucerne hay to cattle after food had been withheld for 2 days. Each inoculum was about 1000 salmonellas, and was given immediately before feeding the animals after starvation for 2 days. The results of one experiment are shown in Fig. 7. The numbers of Salmonella anatum increased over $24 \mathrm{hr}$

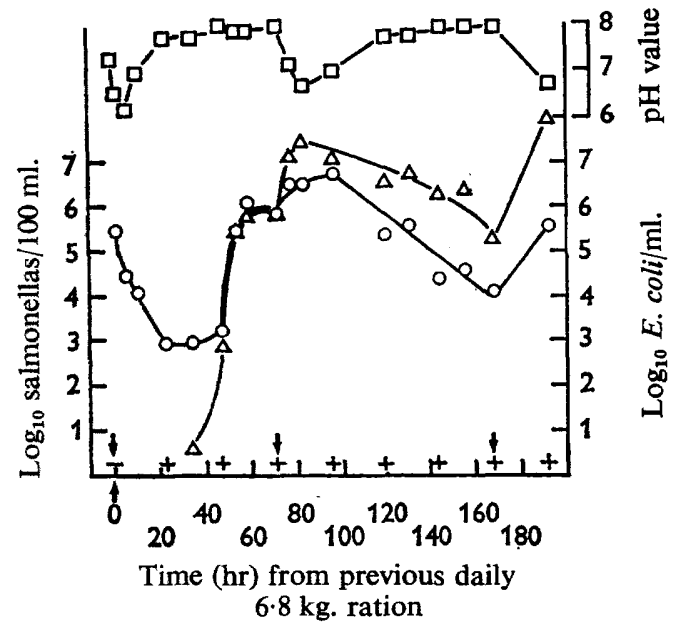

Fig. 5

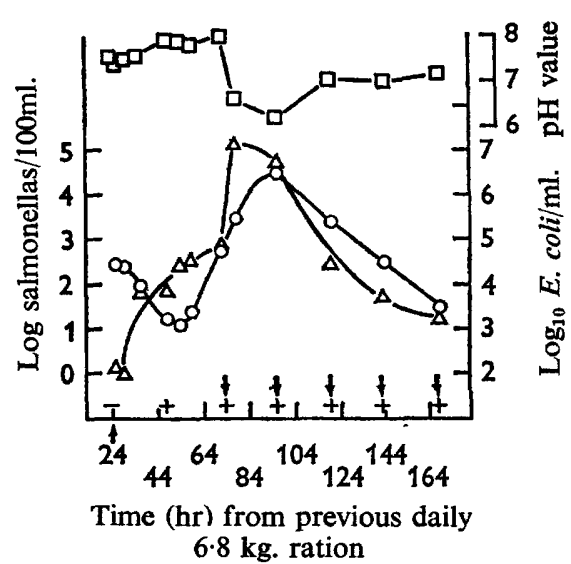

Fig. 6

Fig. 5. Changes in the numbers of Salmonella chester $(O)$ and Escherichia coli type I $(\triangle)$ on inoculation $(\uparrow)$ of $2.07 \times 10^{8}$ salmonellas into the rumen of an animal before feeding $6.8 \mathrm{~kg}$. lucerne hay $(\downarrow)$ and before 2 days without food. + , Salmonellas detected in the faeces; - , not detected in the faeces. $\square, \mathrm{pH}$ value.

Fig. 6. Changes in the numbers of Salmonella oranienburg $(O)$ and Escherichia coli type I $(\triangle)$ on inoculation $(\uparrow)$ of $3.8 \times 10^{5}$ salmonellas into the rumen of an animal $24 \mathrm{hr}$ after feeding and before 2 days without food. $\downarrow$, Fed $6.8 \mathrm{~kg}$. lucerne hay; + , salmonellas detected in faeces; - , salmonellas not detected in faeces. $\square$, pH value.

from an undetectable number to a maximum of $1610 / 100 \mathrm{ml}$. rumen liquor; most of the salmonella growth occurred in the first $6 \mathrm{hr}$. On subsequent feeding the salmonella numbers decreased by about $0.8 \log$ units/day until undetectable. Salmonellas were detected in the faeces at $24 \mathrm{hr}$ after inoculation and for 6 days subsequently; they were not detected after 8 days. Similar results were obtained in the other experiment.

The Escherichia coli type I count increased by about four log units during the starvation period. After feeding, the E. coli count increased rapidly about $2.5 \mathrm{log}$ units to $8.45 \mathrm{log}$ units $/ \mathrm{ml}$. and decreased again on further feeding.

The plot of $\mathrm{pH}$ value against volatile fatty acids for this experiment (Fig. 3) showed two points well below the approximate straight-line relation; these two points (at $\mathrm{pH} 6 \cdot 8$ and 6.3) corresponded to the samples taken at 6 and $11 \mathrm{hr}$ after the feed which followed starvation. It was during this period that rapid growth of Escherichia coli and salmonellas occurred. It appeared that there were considerable amounts of nonvolatile acids present. The major acids detected by chromatography of these rumen 
liquors were lactic, succinic and pyruvic acids, none of which were detected in other rumen samples from the same experiment.

Inoculation of salmonellas before withdrawal for 3 days from lucerne hay or grazing. Three experiments to test the effect of no food for 3 days on the fate of inoculated salmonellas used two animals and three salmonella serotypes. In two of these experiments the animals were inoculated during grazing and then starved for 3 days, whilst in the other experiment the animal was fed the normal lucerne hay ration then inoculated and starved for 3 days.

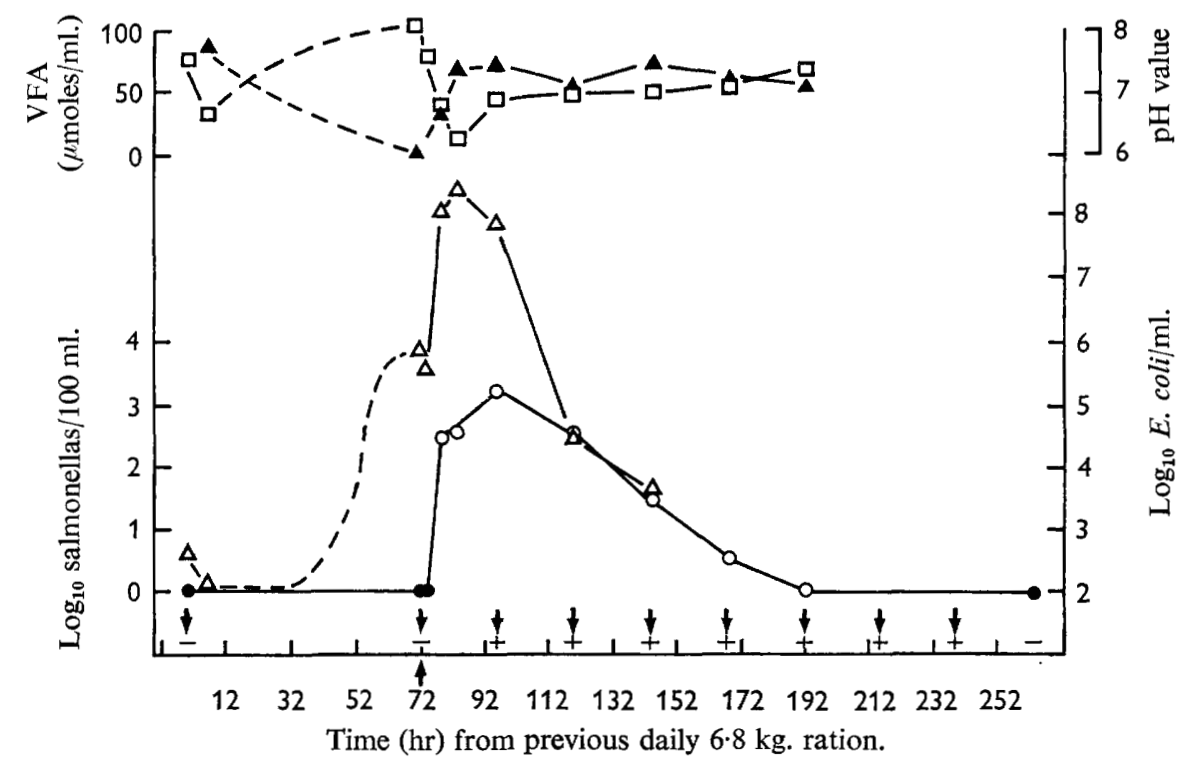

Fig. 7. The effect on inoculated Salmonella anatum $(O)$ of feeding $6.8 \mathrm{~kg}$. lucerne hay/day $(\downarrow)$ after 2 days without food. $\bullet$, Salmonellas not detected in $10 \times 10 \mathrm{ml}$. rumen liquor samples; +, detected in faeces; - , not detected in faeces. $\uparrow$, Time of inoculation with 1130 nutrient broth-grown salmonellas. $\triangle$, Escherichia coli type I count; $\square$, pH value; $\Delta$, VFA, concentration of volatile fatty acids.

Figure 8 shows the results of one grazing experiment in which the inoculum was $4.3 \times 10^{8}$ Salmonella oranienburg, the initial salmonella concentration in the rumen then being $1.61 \times 10^{5} / 100 \mathrm{ml}$. rumen liquor. The animal was returned to grazing for $30 \mathrm{hr}$ after inoculation and was sampled once during this period. The salmonella concentration in the rumen decreased rapidly during grazing and at the beginning of starvation was $10 \cdot 5 / 100 \mathrm{ml}$. rumen liquor. During the next $18 \mathrm{hr}$ the salmonella conconcentration decreased to $1.05 / 100 \mathrm{ml}$. rumen liquor. From this time on the salmonella and Escherichia coli type I numbers increased to $200-300 / 100 \mathrm{ml}$. and $5 \cdot 7 \times 10^{5} / \mathrm{ml}$., respectively. On feeding $6.8 \mathrm{~kg}$. lucerne hay the numbers of salmonellas and $E$. coli increased rapidly to maxima of $3.75 \times 10^{5} / 100 \mathrm{ml}$. and $3.4 \times 10^{7} / \mathrm{ml}$., respectively. The animal took $24 \mathrm{hr}$ to consume the $6.8 \mathrm{~kg}$. lucerne hay, which would normally have been consumed in $2-3 \mathrm{hr}$. The salmonellas and $E$. coli decreased from the maximum concentrations during a further 3 days of food deprivation. Salmonellas were detected in the faeces at $24 \mathrm{hr}$ after inoculation and for the duration of the experiment.

The results of the second grazing experiment were similar except that the time at 
which growth occurred during the starvation period was $40 \mathrm{hr}$ after removal from grazing, as against $18 \mathrm{hr}$ in the previous experiment. In these two experiments the conditions of grazing were different; the experiment illustrated (Fig. 8) being on young green pasture and the second experiment on dry standing pasture.

The results of the experiment with lucerne hay were similar to those of the second experiment (dry standing pasture); the growth of salmonellas and Escherichia coli type I occurred during the starvation period at $48 \mathrm{hr}$ from the last feed.

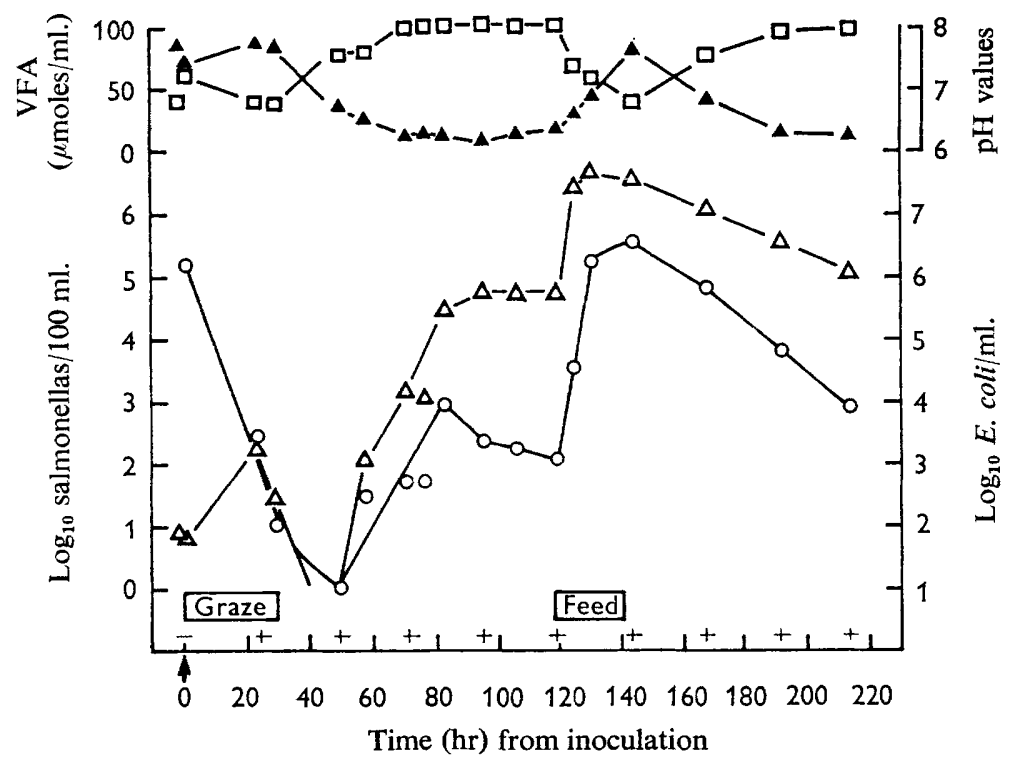

Fig. 8. Changes in the numbers of Salmonella oranienburg $(O)$ and Escherichia coli type I $(\triangle)$ on inoculation $(\uparrow)$ of $4 \cdot 3 \times 10^{8}$ salmonellas into the rumen of an animal allowed to graze for $30 \mathrm{hr}$ ('Graze'), then 3 days without food, and then fed one lot of $6.8 \mathrm{~kg}$. lucerne hay ('Feed'). +, Salmonellas detected in the faeces; - , not detected in the faeces. $\square$, pH value;

$\boldsymbol{\Lambda}$, VFA, concentration of volatile fatty acids.

\section{DISCUSSION}

It is apparent that when the animals were fed $6.8 \mathrm{~kg}$. lucerne hay/day, or were allowed to graze freely, salmonellas were rapidly eliminated from the rumen. The Escherichia coli type I concentrations were usually under $10 / \mathrm{ml}$. rumen liquor when the animals on this feeding regime were restrained in a cattle-crush to prevent ingestion of faecal material. Decrease of the food intake to $2 \cdot 3 \mathrm{~kg}$. hay/day, or deprivation of food for 1 or more days, resulted in maintenance or increases of the salmonella and $E$. coli numbers.

The period for the growth of salmonellas and Escherichia coli to take place during starvation varied with the type of feed. With animals fed lucerne hay salmonellas grew $48-54 \mathrm{hr}$ after feeding and 20 or $40 \mathrm{hr}$ after grazing; the E. coli increases were detected earlier. On feeding after this starvation further increases in numbers of salmonellas and $E$. coli were obtained; the period of most rapid growth was when non-volatile fatty acids were present in the rumen. The average net increases obtained during starvation and subsequent feeding were about $3 \times 10^{4}$-fold for the salmonellas 
and $10^{7}$-fold for $E$. coli, but the total increase in numbers of organisms within the rumen would have been greater considering dilution and passage. Further starvation or feeding caused the concentrations of these organisms to decrease by about one $\log$ unit/day.

Feeding on alternate days (i.e. starvation for one day) tended to stabilize the salmonella concentration after several cycles, while Escherichia coli type I increased from an initial low concentration to between four and five $\log$ units $/ \mathrm{ml}$. There was some evidence of cycling of $E$. coli and possibly of the salmonellas. Increased numbers of $E$. coli were detected within $6 \mathrm{hr}$ after feeding when non-volatile acids were present in the rumen.

Decrease of the feed to $2.3 \mathrm{~kg}$. lucerne hay/day after a period of 4-5 days on reduced feed led to a slow increase in salmonellas and Escherichia coli; a return to $6.8 \mathrm{~kg}$. lucerne hay/day caused an immediate decrease in the numbers of these organisms. This contrasted with the observation that when the animal was starved entirely and then fed $6.8 \mathrm{~kg}$. hay the numbers increased.

There was general agreement in the trends of the numbers of Escherichia coli type I and the salmonellas, although the methods of enumeration were independent. The method of estimating salmonellas by the most-probable-number technique (McCoy, 1962) although laborious, yielded consistent results.

Bergeim, Hanszen, Pincussen \& Weiss (1941) established that volatile fatty acids at low $\mathrm{pH}$ values were bactericidal or bacteriostatic for several genera including salmonellas. Meynell (1963) discussed the findings of Bergeim and others on undissociated volatile fatty acids in relation to the inhibition of Salmonella typhimurium in the normal mouse gut. Wolin (1966) has shown in vitro that the concentration of volatile fatty acids and $\mathrm{pH}$ values found in the bovine rumen inhibit the growth of Escherichia coli. Although the concentration of volatile fatty acids and $\mathrm{pH}$ value may be correlated with changes in numbers of salmonellas in the bovine rumen in conditions of full feed and $2.3 \mathrm{~kg}$. feed, our experiments involving starvation followed by a single feed and further starvation indicated that volatile fatty-acid changes may not be the full explanation. During the first starvation period growth of $E$. coli type I and salmonellas occurred at a $\mathrm{pH}$ value and volatile fatty-acid concentration which were attained again during the second starvation period, when the numbers of the bacteria were actually decreasing (e.g. Fig. 8). There did not seem to be any obvious relation between ammonia concentration in the rumen and growth or death of the organisms.

The growth or death of salmonellas and Escherichia coli type I in the rumen in relation to feeding or starvation may be important in the development of salmonellosis and infections with enteropathogenic $E$. coli, as well as in influencing the incidence of salmonellas found in cattle at slaughter, especially since a low dose of the order of 1000 salmonellas resulted in substantial growth in the rumen and in salmonellas being shed in the faeces for at least a week after dosage. Other experiments have shown that when soil from an abattoir holding-pen was added to the food of a starved animal the salmonella concentrations in the rumen were some hundreds $/ 100 \mathrm{ml}$. rumen liquor and salmonellas were present in the faeces. Conditions which obtain during the transport and holding of cattle before slaughter would appear to predispose these animals to salmonella and $E$. coli infection. 
The authors wish to thank Dr W. J. Scott for helpful discussions, Dr D. R. Lamond and Mr J. H. G. Holmes (C.S.I.R.O., Division of Animal Physiology) for advice and the provision of animals, and P. F. Everson, R. P. Holmes, D. J. Nicol and Beryl W. Stead for technical assistance.

\section{REFERENCES}

Bergeim, O., Hanszen, A. H., Pincussen, L. \& Weiss, E. (1941). Relation of volatile fatty acids and hydrogen sulphide to the intestinal flora. J. infect. Dis. 69, 155.

BRIGGS, P. K., HogAN, J. P. \& REID, R. L. (1957). The effect of volatile fatty acids, lactic acid and ammonia on rumen $\mathrm{pH}$ in sheep. Aust. J. agric. Res. 8, 674.

GORDON, H. T., THORNBURG, W. W. \& WeRUM, L. N. (1962). Rapid paper chromatographic fractionation of complex mixtures of water-soluble substances. J. Chromat. 9, 44.

GraU, F. H. \& BrownLIE, L. E. (1965). Occurrence of salmonellas in the bovine rumen. Aust. vet. J. 41, 321.

McCoY, J. H. (1962). The isolation of salmonellae. J. appl. Bact. 25, 213.

MCKenzie, H. A. \& WALlACE, H. S. (1954). The Kjeldahl determination of nitrogen: a critical study of digestion conditions-temperature, catalyst, and oxidizing agent. Aust.J. Chem. 7, 55.

MANN, S. O., Masson, F. M. \& OXford, A. E. (1954). Facultative anaerobic bacteria from the sheep's rumen. J. gen. Microbiol. 10, 142.

MeYNelL, G. G. (1963). Antibacterial mechanisms of the mouse gut. II. The role of Eh and volatile fatty acids in the normal gut. Br. J. exp. Path. 44, 209.

NEISH, A. C. (1952). Analytical methods for bacterial fermentations. National Research Council of Canada. N.R.C. no. 2952.

RAUN, N. S. \& BURROUGHS, W. (1962). Suction strainer technique in obtaining rumen fluid samples from intact lambs. J. Anim. Sci. 21. 454.

SALISBURY, R. M. (1958). Salmonella infections in animals and birds in New Zealand. N.Z. vet. J. 6, 76. Seddon, H. R. (1953). Salmonelloses. In Diseases of Domestic Animals in Australia, part 5, vol. II. Canberra: Commonwealth of Australia Department of Health.

TING, I. P. \& DUGGer, D. M. (1965). Separation and detection of organic acids on silica gel. Analyt. Biochem. 12, 571.

Varner, J. E., Bulen, W. A., Vanecko, S. \& Burrell, R. C. (1953). Determination of ammonium, amide, nitrite and nitrate nitrogen in plant extracts. Analyt. Chem. 25, 1528.

Woln, M. J. (1966). Volatile fatty acids and the inhibition of Escherichia coli growth by rumen fluid. Bact. Proc. p. 18. 